\title{
Component Improvements in the Electrification of Passenger Vehicles Drivetrains
}

\author{
Thomas Devloo, Niels Leemput, Graduate Student Member, IEEE, Juan Van Roy, Graduate Student Member, IEEE, \\ Frederik Geth, Graduate Student Member, IEEE, and Johan Driesen, Senior Member, IEEE \\ Department of Electrical Engineering (ESAT), Division ELECTA \\ University of Leuven (KU Leuven), 3001 Leuven, Belgium
}

\begin{abstract}
In this paper, possible efficiency improvements of electric components used in drivetrain technologies for passenger vehicles are examined. The fuel consumption is determined for drivetrains with various degrees of electrification, combined with a set of combustion engine technologies. The simulations underline the importance of the energy efficiency of the electric drivetrain to obtain low $\mathrm{CO}_{2}$ emissions. The results help in deciding for which components the research has to focus on regarding efficiency improvements. A large sensitivity to total energy efficiency is observed for the electric motor, battery and power electronics efficiencies.
\end{abstract}

\section{INTRODUCTION}

World-wide, the transport sector consumes approximately $25 \%$ of the total energy use. The sector accounts for about $25 \%$ of the global total end-use energy-related $\mathrm{CO}_{2}$ emissions. Furthermore, transport relies for about $93 \%$ on oil [1]. The number of vehicles will continue to increase, especially in the non-OECD countries. However, the energy demand per vehicle is expected to decrease due to efficiency improvements.

\section{A. Drivetrain architectures}

There are different drivetrain technologies available on the market [2], [3]: vehicles with an internal combustion engine (ICE), electric vehicles (EVs), hybrid and plug-in hybrid electric vehicles (HEVs and PHEVs). An ICE vehicle can be equipped with a gearbox $\left(\mathrm{ICE}_{g}\right)$ or continuously variable transmission ( $\left.\mathrm{ICE}_{\mathrm{CVT}}\right)$. HEVs and PHEVs can have series and/or parallel drivetrains. The Fuel Cell Vehicle (FCV) also exists. Due to the low overall drivetrain efficiency and the required new hydrogen infrastructure, the FCV will not be discussed here.

An ICE with CVT or automatic gearbox is powered by the combustion engine. The major advantage of ICEs is to store a high amount of energy on board, thanks to the high energy density fuel. The disadvantage is the harmful tailpipe emissions, like $\mathrm{CO}, \mathrm{NO}_{\mathrm{X}}$ and $\mathrm{PM}$ [4]. Another problem is the dependency on foreign oil to make gasoline and diesel.

T. Devloo received the M.Sc. degree in Electrical Engineering, with specialization in Energy, from the KU Leuven, Belgium, in 2012.

$\mathrm{N}$. Leemput has a PhD grant of the Institute for the Promotion of Innovation through Science and Technology in Flanders (IWT-Vlaanderen).

J. Van Roy is funded through a doctoral scholarship of the Flemish Institute for Technological Research (VITO), 2400 Mol, Belgium.
Biofuels may be used to obtain a higher flexibility in the fuel production. Biofuels may reduce the greenhouse gas emissions, depending on the production process [5]. In Europe, emission limits (Euro 5 and 6) are introduced for passenger vehicles and light commercial vehicles with respect to the emissions of several pollutants [6].

An EV is powered by an electric motor supplied with electric energy from e.g. a battery. Electricity can be produced in different power plants, e.g. a nuclear power plant, a combined cycle gas turbine (CCGT) plant, photovoltaic systems, etc. The flexibility in primary fuels and types of power plants increases the security of supply. Important advantages of EVs are the absence of tailpipe emissions and the possibility of regenerative braking. Kinetic energy is no longer dissipated as heat, but is recovered through regenerative braking, by using the electric motor in generator mode. The battery pack is heavy for its relatively limited driving range [7].

The series HEV is powered by an electric motor, which can be supplied by both the electricity from a battery or a combustion engine [8]. A generator converts the mechanic energy of the combustion engine in electricity. The combustion engine is typically smaller and operates more efficiently, compared to the engine in an ICE vehicle.

An electric motor or a combustion engine can power the parallel HEV separately [9]. The HEVs can brake regeneratively, but still emit harmful substances. PHEVs have the possibility to recharge their battery from the grid [10]. PHEVs have a limited pure electric range.

\section{B. Available technologies}

1) Electric motors: Three main electric motor types are selected as traction motor for EVs: induction motors (IM), synchronous motors (permanent magnets, PMSM, or external excitation, SM) and switched reluctance motors (SRM) [11], [12]. These motors should fulfill the following requirements: (1) a high power density, (2) a high torque at low speeds and high power at high speeds, (3) a wide speed range, (4) a fast torque response and (5) a high efficiency.

PMSMs are the most efficient and have a very high power density, but are expensive. IMs are very controllable, the technology is very mature and cheap. SRMs have a reliability advantage. Externally excited synchronous machines have a 
high efficiency, but require more maintenance. At low speeds they are competitive with PMSMs due to their high torque density. At high speeds the low losses are comparable to IMs.

2) Batteries: The discussion here is limited to two battery types which have been used in mass market vehicles. To assess battery chemistries, a wide range of characteristics are considered in the literature: storage efficiency (charge acceptance), self-discharge, power capabilities, energy density, energy specific costs, etc [13]. NiMH batteries have been used in HEVs and EVs, because of their technological maturity, high power capabilities and reasonable cost. However, this technology has both a limited efficiency and limited energy density. Lithium chemistries improve on those limiting characteristics and are now commonly used. Li-ion has relatively high energy density, attractive cycle life, low self-discharge and high efficiency. Due to substantial development and experience gained with Li-ion batteries with the introduction of electric vehicles, energy specific prices are expected to keep decreasing in the coming years.

3) Power electronics: Typically, three power electronic interfaces are found in EVs [14]-[16]: (1) a bidirectional motor drive capable of regenerative braking, (2) a bidirectional dc-dc converter connecting the batteries with the DC-bus and (3) a rectifier to charge the batteries. In a non plug-in vehicle, the rectifier is not included. Here, constant efficiency values are considered for the conversion losses.

\section{Scope of the paper}

The scope of this paper is to assess the value of improved electric energy conversion technologies for a passenger car. A simulation model is developed for each drivetrain in MATLAB. Only EVs and (P)HEVs with batteries as energy storage will be discussed. The energy efficiency of the different drivetrains will be compared. For each drivetrain there will be a sensitivity analysis of the parameters of the model.

The following drivetrains are compared on the fuel savings, energy efficiency and $\mathrm{CO}_{2}$ emissions: $\mathrm{ICE}_{g}, \mathrm{ICE}_{\mathrm{CVT}}, \mathrm{EV}$, parallel HEV \& PHEV and series HEV \& PHEV. For the drivetrains with ICE the gasoline, diesel and gas engine are implemented. The same primary energy will be used to compare the EV with the other drivetrains. The fuel of the combustion engine is chosen as primary energy. This fuel will be used in a CCGT power plant (with a $55 \%$ lower heating value efficiency) to produce electricity for the EV.

For a fair comparison, the peak power of the different drivetrains is chosen to be the same, namely $80 \mathrm{~kW}$. The size of the combustion engine in the parallel en series (P)HEV is equal to $50 \mathrm{~kW}$. The motor is downsized compared to the ICE, but is large enough so it can deliver enough power to maintain a steady state speed of $130 \mathrm{~km} / \mathrm{h}$.

\section{MODEL}

\section{A. Drivetrain architectures}

A schematic representation of the $\mathrm{ICE}_{g}$ drivetrain is given in Fig. 1. Between the wheels and the combustion engine are the clutch, gearbox and differential. The models for $\mathrm{ICE}_{g}$ and
ICE $_{\mathrm{CVT}}$ are very similar. The difference is that the gearbox has 7 gear ratios and the CVT can chose the gear ratio between 0.3 and 10 in function of minimum fuel consumption. The combustion engine does not idle. The combustion engine shuts down when the car stands still.

The EV does not have an automatic gearbox or CVT. There is only a differential between the motor and the wheels, which is shown in Fig. 2. The energy management for this drivetrain is very straightforward. In normal conditions the power flow goes from the battery through the electric motor to the wheels. If the EV brakes regeneratively, then the power flow goes from the wheels to the battery.

The series $(\mathrm{P}) \mathrm{HEV}$ is shown schematically in Fig. 3. The energy management algorithm for the series $(\mathrm{P}) \mathrm{HEV}$ is based on existing algorithms and depends on the battery SOC, the requested power at the wheels, the optimal working point of the combustion engine, the battery limitations, etc. [9], [17].

The parallel (P)HEV is shown schematically in Fig. 4. The CVT is placed after the combustion engine. The energy management algorithm is based on existing algorithms and depends on the same parameters as the series (P)HEV, but it also takes the electric motor limitations into account [8], [18].

\section{B. Driving cycles}

The simulation makes use of six different driving cycles, which are summarized in Table I. They represent each a different driving behavior: traffic in a city, suburban traffic and highway traffic. The statistical driving cycles (American cycles) represent more a realistic driving behavior than the artificial driving cycles (European cycles) [19], [20].

For the base case results in section III, the average of the fuel savings, energy efficiency and $\mathrm{CO}_{2}$ emissions for the different driving cycles is taken. However, for the sensitivity analysis, the fuel consumption is calculated for a combined cycle of the UDDS, NYCC and HWFET cycles. It is assumed that the vehicle drives each cycle for the same duration [20].

\section{Parameters}

The design parameters of the car are based on a Nissan Leaf and are displayed in Table II. The mass of each component is taken into account to determine the total mass of the vehicle [21], [22]. In the simulation, two batteries are used, respectively for the (P)HEV [23] and EV [24]. The battery pack sizes are based on existing vehicles: the Nissan Leaf for an EV (24 kWh usable) and the (Plug-in) Toyota Prius for a

TABLE I

OVERVIEW OF THE DIFFERENT TEST DRIVING CYCLES

\begin{tabular}{llrrr}
\hline Cycle & Type & Distance & Time & Avg. speed \\
\hline ECE-EU & Highway & $17.243 \mathrm{~km}$ & $900 \mathrm{~s}$ & $68.97 \mathrm{~km} / \mathrm{h}$ \\
ECE-ELEM & Suburban & $3.746 \mathrm{~km}$ & $395 \mathrm{~s}$ & $34.15 \mathrm{~km} / \mathrm{h}$ \\
UDDS & Suburban & $11.990 \mathrm{~km}$ & $1370 \mathrm{~s}$ & $31.51 \mathrm{~km} / \mathrm{h}$ \\
NYCC & City & $1.898 \mathrm{~km}$ & $598 \mathrm{~s}$ & $11.43 \mathrm{~km} / \mathrm{h}$ \\
CUC & Suburban & $15.797 \mathrm{~km}$ & $1435 \mathrm{~s}$ & $39.63 \mathrm{~km} / \mathrm{h}$ \\
HWFET & Highway & $16.507 \mathrm{~km}$ & $765 \mathrm{~s}$ & $77.68 \mathrm{~km} / \mathrm{h}$ \\
\hline
\end{tabular}




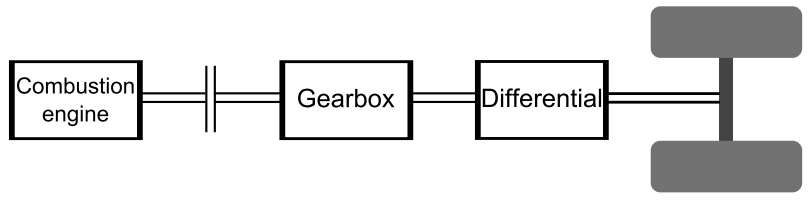

Fig. 1. Schematic scheme of an $\mathrm{ICE}_{g}$ drivetrain. An $\mathrm{ICE}_{\mathrm{CVT}}$ has a similar setup with a CVT instead of an automatic gearbox.

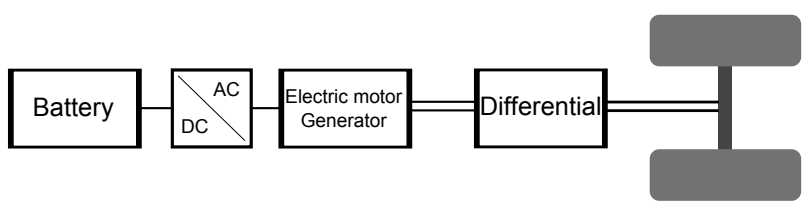

Fig. 2. Schematic scheme of an EV drivetrain.

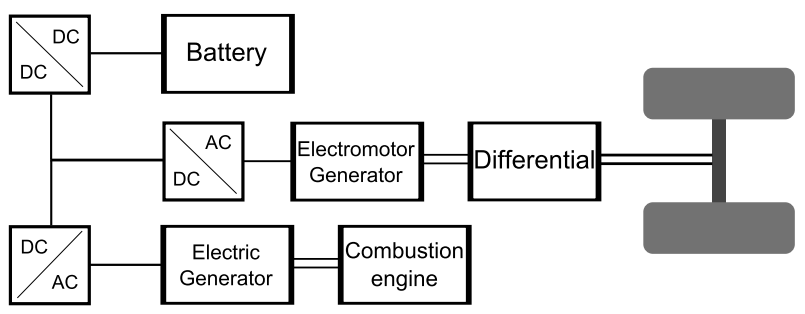

Fig. 3. Schematic scheme of a series (P)HEV drivetrain.

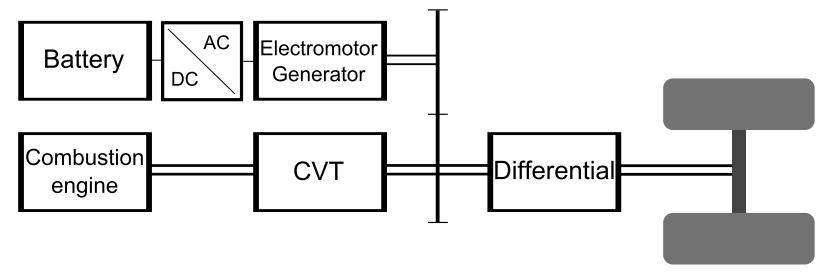

Fig. 4. Schematic scheme of a parallel (P)HEV drivetrain

(P)HEV (1.4 and $4.4 \mathrm{kWh}$ ) [25]. The total mass of the Nissan Leaf is $1521 \mathrm{~kg}$. The mass without engine and batteries of the Nissan Leaf is estimated at $1183 \mathrm{~kg}$. For the different drivetrains, the total mass varies between 1391 and $1488 \mathrm{~kg}$.

The efficiencies of the components used in the drive trains are shown in Table III [26]-[28]. The value for the differential ratio is respectively $2.24,3.07$ and 5.5 for the diesel ICE, gasoline ICE and $(\mathrm{P})(\mathrm{H}) \mathrm{EV}$.

An efficiency map is used for the different combustion

TABLE II

DESIGN PARAMETERS OF THE VEHICLE.

\begin{tabular}{cccc}
\hline $\begin{array}{c}\text { Frontal } \\
\text { area S }\end{array}$ & $\begin{array}{c}\text { Air resistance } \\
\text { coefficient } \mathbf{c}_{d}\end{array}$ & $\begin{array}{c}\text { Rolling } \\
\text { resistance } \mathbf{c}_{r}\end{array}$ & $\begin{array}{c}\text { Radius } \\
\text { wheel } \mathbf{r}_{w}\end{array}$ \\
\hline $2.32 \mathrm{~m}$ & 0.29 & 0.010 & $0.32 \mathrm{~m}$ \\
\hline
\end{tabular}

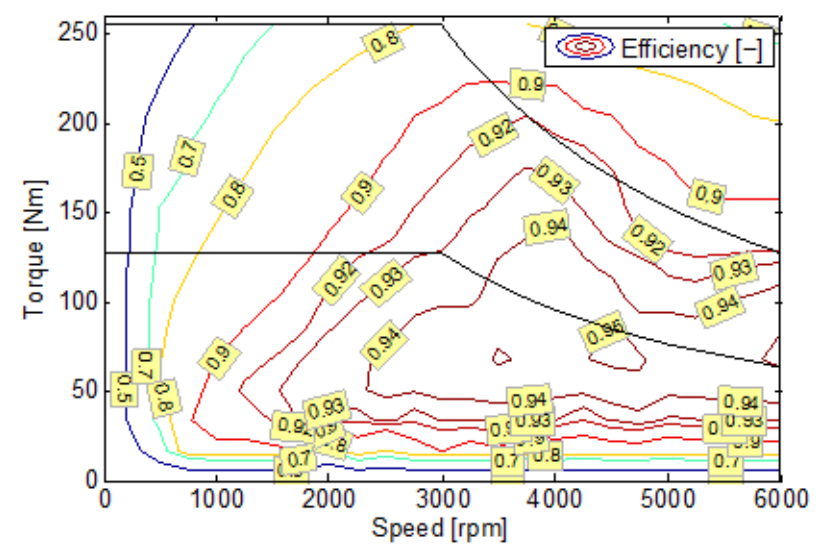

Fig. 5. The measured efficiency map of the electric motor.

engines [29] ${ }^{1}$. The measured efficiency map of the electric motor is shown in Fig. 5. The electric motor, a PMSM, has an original power of $11 \mathrm{~kW}$. For the overload conditions, the map is based on the efficiency map of the Toyota Prius electric motor [30]. The torque of the combustion engines and electric motor are scaled to obtain the desired motor size.

\section{Results FOR the BAse CASe PARAmeters}

In this section, the results for the different drive trains are discussed in terms of fuel, energy efficiency and $\mathrm{CO}_{2}$ emissions for both gasoline and diesel powered vehicles.

\section{A. Drivetrains with gasoline engine}

The $\mathrm{ICE}_{g}$ consumes on average $5.371 / 100 \mathrm{~km}$ gasoline on the driving cycles. The fuel savings of the drivetrains with gasoline engine compared to the $\mathrm{ICE}_{g}$ are shown in Fig. 6.

The fuel savings for the $\mathrm{ICE}_{\mathrm{CVT}}$ and the series $(\mathrm{P}) \mathrm{HEV}$ are limited. The disadvantage of the series $(\mathrm{P}) \mathrm{HEV}$ is that there are a lot of components between the gasoline engine and the wheels which all have their respective efficiency. For the PHEVs, the fuel consumption during CS-mode (charge sustaining mode) is considered. For the parallel HEV, the fuel savings compared to the $\mathrm{ICE}_{g}$ is $15 \%$. The reason for the higher fuel consumption of the parallel PHEV compared to the $\mathrm{HEV}$ is that the gasoline engine works more in points with a lower SFC (specific fuel consumption). If the speed of the vehicles is low and the torque to the electric motor is high, the efficiency of the electric motor will be low. Compared to an $\mathrm{ICE}_{g}$, an EV has a fuel saving of $37 \%$.

${ }^{1}$ Audi 3.0L TFSI V6 and Audi 4.2L TDI V8.

TABLE III

EFFICIENCY [\%] OF THE DIFFERENT DRIVETRAIN COMPONENTS.

\begin{tabular}{cccccc}
\hline Gearbox & CVT & $\begin{array}{c}\text { Power } \\
\text { electronics }\end{array}$ & $\begin{array}{c}\text { Battery } \\
\text { charging }\end{array}$ & $\begin{array}{c}\text { Wheel } \\
\text { friction }\end{array}$ & $\begin{array}{c}\text { Differential } \\
\eta_{g}\end{array}$ \\
$\eta_{C V T}$ & $\eta_{p e}$ & $\eta_{b a t}$ & $\eta_{w}$ & $\eta_{\text {dif }}$ \\
\hline 94.0 & 93.0 & 97.5 & 94.9 & 98.0 & 97.0 \\
\hline
\end{tabular}




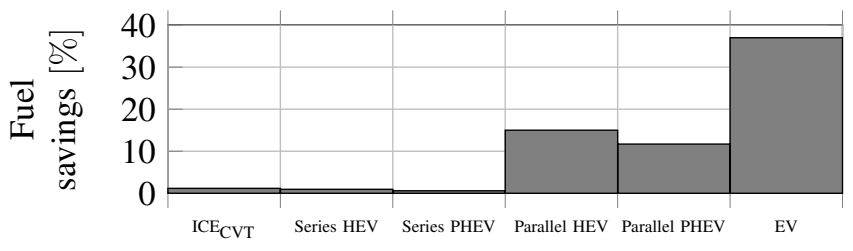

Fig. 6. Fuel savings of the different gasoline drivetrains compared to the $\mathrm{ICE}_{g}$.

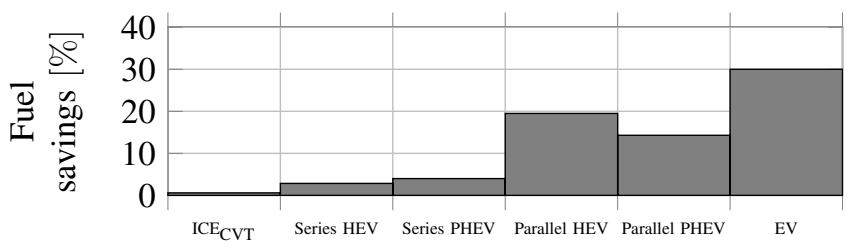

Fig. 7. Fuel savings of the different diesel drivetrains compared to the $\mathrm{ICE}_{g}$.

\section{B. Drivetrains with diesel engine}

The $\mathrm{ICE}_{g}$ consumes on average $4.39 \mathrm{l} / 100 \mathrm{~km}$ diesel on the driving cycles. The fuel savings of the drivetrains with diesel engine compared to the $\mathrm{ICE}_{g}$ are shown in Fig. 7.

The fuel savings for the HEVs are larger for a diesel engine than for a gasoline engine. The reason is that the point of minimum SFC occurs at a larger output power value compared to the gasoline engine. For a regular $\mathrm{ICE}_{g}$, the point of minimum SFC is used more often by a gasoline engine, thus the possible improvements in fuel savings are higher for diesel HEVs. The fuel savings for the EV are smaller compared to the gasoline engine, because the diesel engine works on average with a higher efficiency.

\section{Energy efficiency}

In Fig. 8, the energy savings of a parallel HEV on natural gas and diesel and an EV are compared to a parallel HEV on gasoline. The energy efficiency does not only depend on the drivetrain, but also on the ICE and its fuel. Diesel fueled engines have the highest energy efficiency, whereas gas fueled ones have the lowest energy efficiency. If the electricity for an EV would be generated in a CCGT power plant, the EV drivetrain is considered the most energy efficient.

\section{D. $\mathrm{CO}_{2}$ emissions}

In Fig. 9, the $\mathrm{CO}_{2}$ emissions avoided of a parallel HEV on natural gas and diesel and an EV are compared to parallel HEV on gasoline. The parallel HEV gasoline emits on average $9.41 \mathrm{~kg} \mathrm{CO} / 100 \mathrm{~km}$. With the average $\mathrm{CO}_{2}$ emissions of the Belgian power generation park [31], the EV emits the least $\mathrm{CO}_{2}$. Although the parallel $\mathrm{HEV}$ gas uses the most primary energy, it emits the least $\mathrm{CO}_{2}$ of all parallel $\mathrm{HEV}$, since natural gas has a lower carbon intensity. Gasoline has a lower $\mathrm{CO}_{2}$ content per amount of energy compared to diesel. But because of the difference in fuel consumption, the drivetrains with gasoline engines emit more $\mathrm{CO}_{2}$.

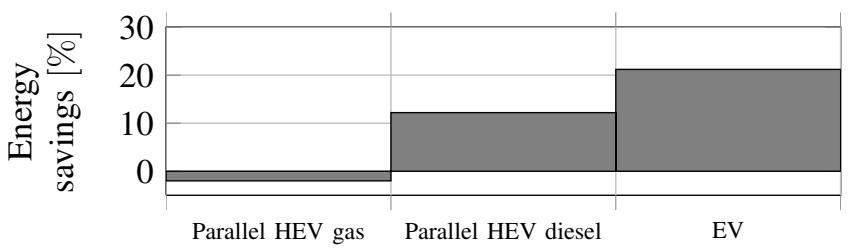

Fig. 8. Energy savings of a Parallel HEV gas \& diesel and EV compared to a Parallel HEV gasoline.

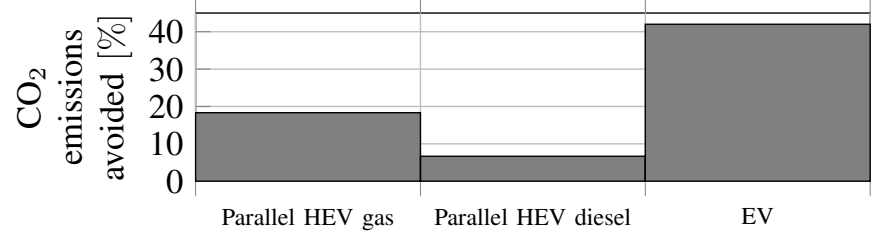

Fig. 9. $\mathrm{CO}_{2}$ emissions avoided of a Parallel HEV gas \& diesel and EV compared to a Parallel HEV gasoline.

\section{Sensitivity AnAlysis}

In this section, a sensitivity analysis is performed on the different parameters and discussed in terms of fuel consumption and driving range of the vehicles.

\section{A. Car and combustion engine design parameters}

The sensitivity of the frontal area $(\mathrm{S})$, drag coefficient $\left(\mathrm{c}_{d}\right)$, mass $(\mathrm{M})$, rolling resistance coefficient $\left(\mathrm{c}_{r}\right)$ and SFC of the combustion engine on the fuel consumption is approximately the same for all drivetrains. Table IV shows the $\mathrm{ICE}_{g}$ results.

The variation of the fuel consumption is always linear. However, a larger sensitivity can be noted for a positive increase of the parameter. This is due to the fact that the combustion engine has worse SFC values for low load compared to high load. If the mass of the car increases, the requested power rises and the combustion engine working points have better SFC values and vice versa.

For the sensitivity analysis of the SFC, the efficiency map is changed by a certain percentage. Thus, the place of the working points of the combustion engines do not change. The fuel consumption improves with $3 \%$ if the frontal area or drag coefficient reduces with $10 \%$. These two coefficients have the same impact, because they occur in one and the same force acting on the vehicle, namely the air friction component. The impact of the mass is higher, since the mass is present in all the force components, except the air friction.

TABLE IV

SENSITIVITY ANALYSIS OF THE CAR AND COMBUSTION ENGINE DESIGN PARAMETERS TO THE FUEL CONSUMPTION [\%].

\begin{tabular}{lcccc}
\hline & $\mathbf{- 1 0} \%$ & $\mathbf{- 1} \%$ & $\mathbf{+ 1} \%$ & $\mathbf{+ 1 0} \%$ \\
\hline $\mathrm{S} \mathrm{\&} \mathrm{c}_{d}$ & -3.01 & -0.30 & +0.30 & +3.03 \\
$\mathrm{M}$ & -5.46 & -0.55 & +0.55 & +5.56 \\
$\mathrm{c}_{r}$ & -2.46 & -0.25 & +0.25 & +2.49 \\
$\mathrm{SFC}$ & -10.00 & -1.00 & +1.00 & +10.00 \\
\hline
\end{tabular}




\section{B. Wheel and differential parameters}

The sensitivity of the wheel friction efficiency on the fuel consumption is shown for some drivetrains in Table V. It can be noted that the wheel friction has a larger sensitivity for the drivetrains with an electric motor compared to drivetrains without an electric motor. This is because the drivetrains with electric motor can brake regeneratively, for which the wheel efficiencies are also important. An identical conclusion can be made for the differential parameter.

\section{Electric motor parameters}

The sensitivity of the electric motor efficiency is shown in Table VI for all the drivetrains with an electric motor. The characteristic efficiency map of the electric motor is not changed in shape; all efficiency values in the map are multiplied by the given percentage. For the series HEV, a distinction is made between the generator near the combustion engine (Gen) and the electric motor near the differential (MG).

The sensitivity to electric motor efficiency is high for the EV as well as for the series (P)HEV MG. For these drivetrains, only the electric motor can deliver power to the wheels. The difference between these drivetrains is that in the EV the power comes from the battery, whereas in the series (P)HEV it comes from the ICE. For parallel drivetrain architectures, the impact is higher for the plug-in version than for the pure hybrid.

\section{Battery parameters}

The sensitivity to the battery efficiency is shown in Table VII for all the drivetrain architectures containing a battery. The sensitivity of the storage efficiency for the EV and parallel HEV is very similar to the sensitivity of the electric motor efficiency. For the series PHEV, the sensitivity is higher than that of the series HEV, because the energy management strategy uses the battery more compared to the series HEV.

\section{E. Power electronics parameters}

The sensitivity to the power electronics efficiency is shown in Table VIII. For the series (P)HEV, a distinction is made between the power electronic converters near the generator (Gen), near the electric motor (EM) and near the battery (Bat). The sensitivity of the power electronics efficiency for the EV, the series (P)HEV EM, the series (P)HEV Gen and the parallel $\mathrm{HEV}$ is similar in value to the sensitivity of the electric motor efficiencies. The sensitivity of the series (P)HEV Bat is about the same as the sensitivity of the battery efficiency.

\section{Discussion on Component Design}

The results in Section III and IV are discussed shortly from the point of view of the design of components used in the different drivetrain technologies.

\section{A. Combustion engine}

Increasing the SFC of the combustion engine improves the fuel consumption. Identical ICE efficiency maps are used for ICE and HEV drivetrains. In reality these engines would have different designs. Conventional ICE vehicles need a
TABLE V

SENSITIVITY ANALYSIS OF THE WHEEL EFFICIENCY TO THE FUEL CONSUMPTION [\%].

\begin{tabular}{lcccc}
\hline & $\mathbf{- 2} \mathbf{p p}$ & $\mathbf{- 1} \mathbf{p p}$ & $\mathbf{+ 1} \mathbf{p p}$ & $\mathbf{+ 2} \mathbf{p p}$ \\
\hline $\mathrm{ICE}_{g}$ & +1.80 & +0.89 & -0.87 & -1.72 \\
$\mathrm{ICE}_{\mathrm{CVT}}$ & +1.91 & +0.95 & -0.93 & -1.83 \\
$\mathrm{EV}$ & +2.61 & +1.29 & -1.27 & -2.51 \\
Parallel HEV & +2.38 & +1.19 & -1.19 & -2.38 \\
Series HEV & +2.23 & +1.11 & -1.11 & -2.23 \\
\hline
\end{tabular}

TABLE VI

SENSITIVITY ANALYSIS OF THE ELECTRIC MOTOR EFFICIENCY TO THE FUEL CONSUMPTION [\%].

\begin{tabular}{lcccc}
\hline & $\mathbf{- 5} \%$ & $\mathbf{- 1} \%$ & $\mathbf{+ 1} \%$ & $\mathbf{+ 5} \%$ \\
\hline EV & +6.86 & +1.32 & -1.30 & -6.28 \\
Parallel HEV & +1.86 & +0.37 & -0.37 & -1.85 \\
Series HEV MG & +5.76 & +1.15 & -1.15 & -5.76 \\
Series HEV Gen & +4.72 & +0.94 & -0.94 & -4.72 \\
Parallel PHEV & +3.86 & +0.77 & -0.77 & -3.86 \\
Series PHEV MG & +5.93 & +1.19 & -1.19 & -5.93 \\
Series PHEV Gen & +5.14 & +1.03 & -1.03 & -5.14 \\
\hline
\end{tabular}

TABLE VII

SENSITIVITY ANALYSIS OF THE BATTERY EFFICIENCY TO THE FUEL CONSUMPTION [\%].

\begin{tabular}{lcccc}
\hline & $\mathbf{- 5} \mathbf{p p}$ & $\mathbf{- 1} \mathbf{p p}$ & $\mathbf{+ 1} \mathbf{~ p p}$ & $\mathbf{+ 5} \mathbf{~ p p}$ \\
\hline EV & +7.25 & +1.40 & -1.37 & -6.61 \\
Parallel HEV & +2.07 & +0.41 & -0.41 & -2.07 \\
Series HEV & +3.63 & +0.72 & -0.72 & -3.63 \\
Parallel PHEV & +4.09 & +0.82 & -0.82 & -4.09 \\
Series PHEV & +5.10 & +1.17 & -1.17 & -5.10 \\
\hline
\end{tabular}

TABLE VIII

SENSITIVITY ANALYSIS OF THE POWER ELECTRONICS EFFICIENCY ON THE FUEL CONSUMPTION [\%].

\begin{tabular}{lcccc}
\hline & $\mathbf{- 2} \mathbf{p p}$ & $\mathbf{- 1} \mathbf{p p}$ & $\mathbf{+ 1} \mathbf{p p}$ & $\mathbf{+ 2} \mathbf{p p}$ \\
\hline EV & +2.74 & +1.36 & -1.33 & -2.64 \\
Parallel HEV & +0.76 & +0.38 & -0.38 & -0.76 \\
Series HEV EM & +2.35 & +1.18 & -1.18 & -2.35 \\
Series HEV Gen & +1.95 & +0.97 & -0.97 & -1.95 \\
Series HEV Bat & +1.39 & +0.70 & -0.70 & -1.39 \\
Parallel PHEV & +1.41 & +0.71 & -0.71 & -1.41 \\
Series PHEV EM & +2.48 & +1.24 & -1.24 & -2.48 \\
Series PHEV Gen & +1.88 & +0.94 & -0.94 & -1.88 \\
Series PHEV Bat & +2.05 & +1.03 & -1.03 & -2.05 \\
\hline
\end{tabular}

good efficiency in a relatively broad power range. For HEV drivetrains, the optimal ICE design has a high peak efficiency in a small operating range.

\section{B. Electric motor}

Due to the high sensitivity to the fuel consumption for EVs and series (P)HEVs, highly efficient motors should be chosen, such as a PMSM. When the sensitivity is lower, it is important to choose a motor to find the balance between 
efficiency, cost, reliability, maintenance, and the sensitivity of the other components in the drivetrain architecture. Induction motors are a very mature technology with good characteristics and a low cost, while SMs require higher maintenance.

\section{Battery}

The storage efficiency of the batteries in EVs and PHEVs has a high sensitivity to the fuel consumption and the electric range. A combined design approach, matching the battery pack to its power electronic converter and vice versa, is considered a pathway for further improvement. However, the trade-off of cost versus efficiency for batteries in HEVs is leaning more towards to cost minimization, because of the lower sensitivity compared to EVs and PHEVs.

\section{Power Electronics}

The sensitivity of the fuel consumption to the power electronic efficiency is high for EVs and series (P)HEVs EM/Gen. These converters could be made more efficiently with new and more efficient semiconductor technologies such as $\mathrm{SiC}$ or $\mathrm{GaN}$. Improved converters may also be used in parallel PHEV Bat and series PHEV Bat, because there they have a significant impact on the electric driving range.

\section{CONCLUSIONS}

In this paper, possible efficiency improvements of electric components used in drivetrain technologies for passenger vehicles are examined. The fuel consumption is determined for drivetrains with various degrees of electrification, combined with a set of combustion engine technologies. For each drivetrain, a sensitivity analysis is performed for the parameters of the model. The results help in deciding for which components the research has to focus on regarding efficiency improvements. A large sensitivity is observed for the electric motor, battery and power electronics efficiencies.

Nevertheless, the general trend in vehicles is to go to smaller, lighter and more aerodynamic designs. The sensitivity of these parameters is approximately the same for all drivetrains. Fuel efficiency can not only be improved through the choice of the drivetrain technology, but also through the design of the car. The comparison of the different drivetrains confirms that the pure electric drivetrain is the most energy efficient and has low $\mathrm{CO}_{2}$ emissions, followed by the parallel (P)HEV. The parallel hybrid drivetrains have a reduced fuel consumption of approximately $20 \%$ compared to the $\mathrm{ICE}_{g}$. $\mathrm{HEV}$ drivetrain technology reduces the problem of emissions, but additional measures must be considered where the impact of emissions remains substantial: namely in urban areas.

\section{REFERENCES}

[1] "Energy Technology Perspectives 2012: Pathways to a Clean Energy System," International Energy Agency, Tech. Rep., 2012.

[2] "Powering Autos to 2020: The Era of the Electric Car," Boston Consulting Group, Tech. Rep., Jul. 2011.

[3] "The Comeback of the Electric Car? How Real, How Soon, and What Must Happen Next," Boston Consulting Group, Tech. Rep., 2009.
[4] B. K. Sovacool, "A Transition to Plug-In Hybrid Electric Vehicles (PHEVs): Why Public Health Professionals Must Care," J. of Epidemiology and Community Health, Vol. 64, no. 3, Mar. 2010.

[5] F. Cherubini, N.D. Bird, A. Cowie, G. Jungmeier, B. Schlamadinger, and S. Woess-Gallasch, "Energy- and Greenhouse Gas-Based LCA of Biofuel and Bioenergy Systems: Key Issues, Ranges and Recommendations," Resources, Conservation and Recycling, Vol. 53, no. 8, pp. 434-447, Jun. 2009.

[6] European Commission. (2013, Mar. 22) Automotive: Euro 5 and Euro 6 emissions from light duty vehicles. [Online]. Available: http://ec.europa. eu/enterprise/sectors/automotive/environment/euro5/index_en.htm.

[7] A. G. Boulanger, A. C. Chu, S. Maxx, and D. L. Waltz, "Vehicle Electrification: Status and Issues," Proc. IEEE, Vol. 99, no. 6, pp. 1116-1138, May 2011.

[8] N. Jalil, N. Kheir, and M. Salman, "A Rule-Based Energy Management Strategy for a Series Hybrid Vehicle," in Proc. of the Amer. Control Conf., Albuquerque, New Mexico, Jun. 1997.

[9] M. Salman, and N. Schouten, "Control Strategies for Parallel Hybrid Vehicles," in Proc. of the Amer. Control Conf., Chicago, USA, Jun. 2010.

[10] S. Lukic, J. Cao, and R. Bansal, "Energy Storage Systems for Automotive Applications," IEEE Trans. Ind. Electron., Vol. 55, no. 6, pp. 2258-2267, Jun. 2008

[11] M. Zeraoulia, M. E. H. Benbouzid, and D. Diallo, "Electric motor drive selection issues for HEV propulsion systems: A comparative study," IEEE Trans. Veh. Technol., vol. 55, no. 6, pp. 1756-1764, Nov. 2006.

[12] Z. Q. Zhu and D. Howe, "Electrical machines and drives for electric, hybrid, and fuel cell vehicles," Proc. IEEE, vol. 95, no. 4, pp. 746-765, Apr. 2007.

[13] Battery University. (2013, Mar. 22) [Online]. Available: http://www. batteryuniversity.com.

[14] C. C. Chan, "The state of the art of electric, hybrid, and fuel cell vehicles," Proc. IEEE, vol. 95, no. 4, pp. 704718, Apr. 2007.

[15] M. Ehsani, Y. Gao, and J. M. Miller, "Hybrid electric vehicles: Architecture and motor drives," Proc. IEEE, vol. 95, no. 4, pp. 719728 Apr. 2007.

[16] A. Emadi and K. Rajashekara, "Power electronics and motor drives in electric, hybrid electric, and plug-in hybrid electric vehicles," IEEE Trans. Ind. Electron., vol. 55, no. 6, pp. 22372245, Jun. 2008.

[17] H. Banvait, and S. Anwar, "A Rule-Based Energy Management Strategy for Plug-In Hybrid Electric Vehicle (PHEV)," in Amer. Control Conf., St. Louis, USA, Jun. 2009.

[18] P. Caratozzolo, and M. Serra, "Energy Management Strategies for Hybrid Electric Vehicles," IEEE Int. Electric Mach. and Drives Conf., Madison, USA, Jun. 2003.

[19] U.S. Environmental Protection Agency. (2013, Mar. 22) Dynamometer Driver's Aid. [Online]. Available: http://www.epa.gov/nvfel/testing/.

[20] E. G. Giakoumis, and A. I. Alafouzos, "Study of diesel engine performance and emissions during a Transient Cycle applying an engine mapping-based methodology," Appl. Energy, Vol. 87, no. 4, pp. 1358-1365, Apr. 2010.

[21] Nissan. (2013, Mar. 22) Nissan Leaf Specs. [Online]. Available: http: //www.nissan-zeroemission.com/EN/LEAF/specs.html.

[22] National Research Council. Tires and Passenger Vehicle Fuel Economy: Informing Consumers, Improving Performance - Special Report 286 Washington, DC: The National Academies Press, 2006.

[23] LiFeBATT, "XPS2E-144015 Technical Specification," 2011.

[24] LiFeBATT, "X-2E 15Ah 40166 Cell - Technical Specification," 2009.

[25] Toyota. (2013, Mar. 22) Toyota Prius - 2012 Performance and Specifications. [Online]. Available: http://www.toyota.com/.

[26] R.P.G. Heath, "Seamless AMT offers efficient alternative to CVT," in JSAE Annu. Congr., Yokohama, Japan, May 2007.

[27] A. Pearlman. (2013, Mar. 22) Car Differential. [Online]. Available: http: //web.mit.edu/2.972/www/reports/differential/differential.html.

[28] Fronius. (2013, Mar. 22) Technical Data IG TL 3.0. [Online]. Available: http://www.fronius.com/cps/rde/xchg/SID-4CD37561-E779C47E/ fronius international/hs.xsl/83_16685 ENG_HTML.htm

[29] AMT.nl. (2013, Mar. 22) [Online]. Available: http://www.amt.nl.

[30] M. Olszewski, "Evaluation of 2004 Toyota Prius Hybrid Electric Drive System," Oak Ridge National Laboratory, Tech. Rep. ORNL/TM-2006/423, 2006.

[31] Carbon Monitoring for Action. (2013, Mar. 22) Power Trends Belgium. [Online]. Available: http://carma.org. 